\title{
PENGARUH KOMPETENSI DAN PENGAWASAN TERHADAP PRODUKTIVITAS KERJA KARYAWAN PADA PT. XYLO INDAH PRATAMA KABUPATEN MUSI RAWAS
}

\author{
Nasruddin $^{1}$, Wiwik Wahyuni ${ }^{2}$ \\ 1,2Program Studi Manajemen, Universitas Bina Insan Lubuklinggau \\ E-mail : ${ }^{1}$ nasruddin@univbinainsan.ac.id, ${ }^{2}$ wiwikwahyuni@gmail.com
}

\begin{abstract}
ABSTRACK
This study aims to determine the effect of competence and supervision on employee work productivity at PT Xylo Indah Pratama, Musi Rawas Regency partially and simultaneously. The method used is a quantitative method. Questionnaire data collection techniques. The results of the research.Testing the first hypothesis to determine whether the competence of employee work productivity, the tcount value is 7,476 and the ttable is 1,292 (ttable value $n=77$ ), so it can be seen that if the criteria match tcount> ttable then Ho is rejected and Ha is accepted. , meaning that there is an influence of competence on employee work productivity. The second hypothesis testing is to determine the effect of supervision on employee work productivity. The results obtained tcount value of 11.809 and ttable is 1.292 (ttable value $n=77$ ) so it can be seen that if the criteria are in accordance with tcount> ttable then Ho is rejected and Ha is accepted, meaning that there is a supervisory effect on employee work productivity at PT Xylo Indah. Primary of Musi Rawas Regency. The third hypothesis is to determine the effect of competence and supervision on work productivity. Obtained the value of Fcount of 70,986 and Ftable of 3.12 This shows that Fcount> Ftable and also sig of $0.000<0.05$ so it can be seen that the effect is significant. Thus, it can be concluded that Ho is rejected and Ha is accepted. This means that there is an influence of competence and supervision on employee work productivity.
\end{abstract}

Keywords : Competence, Supervision, Work Productivity

\begin{abstract}
ABSTRAK
Penelitian ini bertujuan untuk mengetahui pengaruh kompetensi dan pengawasan terhadap produktivitas kerja karyawan di PT Xylo Indah Pratama Kabupaten Musi Rawas secara parsial dan simultan. Metode yang digunakan adalah metode kuantitatif. Teknik pengumpulan data kuisioner. Hasil penelitian Pengujian hipotesis pertama untuk mengetahui apakah kompetensi terhadap produktivitas kerja karyawan, didapatkan nilai $t_{\text {hitung }}$ sebesar 7.476 dan tabel adalah sebesar 1,292 (nilai $t_{\text {tabel }} \mathrm{n}=77$ ) maka dengan demikian dapat diketahui bahwa jika kriteria sesuai dengan $\mathrm{t}_{\text {hitung }}>\mathrm{t}_{\text {tabel }}$ maka Ho ditolak dan Ha diterima, artinya terdapat pengaruh kompetensi terhadap produktivitas kerja karyawan. Pengujian hipotesis kedua untuk mengetahui pengaruh pengawasan terhadap produktivitas kerja karyawan. Hasil didapatkan nilai $t_{\text {hitung }}$ sebesar 11.809 dan $t_{\text {tabel }}$ adalah sebesar 1,292 (nilai $t_{\text {tabel }} n=77$ ) maka dengan demikian dapat diketahui bahwa jika kriteria sesuai dengan $t_{\text {hitung }}>t_{\text {tabel }}$ maka Ho ditolak dan Ha diterima, artinya terdapat pengaruh pengawasan terhadap produktivitas kerja karyawan pada PT Xylo Indah Pratama Kabupaten Musi Rawas. Hipotesis ketiga untuk mengetahui pengaruh kompetensi dan pengawasan terhadap produktivitas kerja. Diperoleh nilai $F_{\text {hitung }}$ sebesar 70.986 dan $F_{\text {tabel }}$ sebesar 3.12 Ini menunjukan bahwa $F_{\text {hitung }}>$ $F_{\text {tabel }}$ dan juga sig sebesar $0,000<0,05$ sehingga dapat diketahui bahwa pengaruhnya signifikan. Maka dengan demikian dapat diambil kesimbulan bahwa Ho ditolak dan Ha diterima. Artinya terdapat pengaruh kompetensi dan pengawasan terhadap produktivitas kerja karyawan.
\end{abstract}

Kata kunci : Kompetensi, Pengawasan, Produktivitas Kerja 


\section{PENDAHULUAN}

Kompetensi Menurut Sudarmanto (2015:44) adalah terminologi yang sering didengar dan diucapkan banyak orang. Kita pun sering mendengar dan mengucapkan terminologi itu dalam berbagai penggunaan, khususnya tarkait dengan pengembangan sumber daya manusia. Akan tetapi sering kali persepsi, pemahaman dan makna terminology itu tidak sama atau saling dipertukarkan dengan terminologi lain.

Karyawan dalam bekerja juga membutukan pengawasan agar mampu lebih teliti dan terarah dalam menyelesaikan pekerjaan sehingga karyawan dapat mencapai produktivitas kerja yang optimal. Menurut Sedarmayanti (2017: 197) pengawasan SDM merupakan kegiatan yang dilakukan untuk mengendalikan pelaksanaan tugas/pekerjaan yang dilakukan seseorang agar proses pekerjaan sesuai dengan hasil yang diingiinkan, dengan pengawasan tersebut maka karyawan akan mampu meningkatkan kualitas kerja karyawan demi mencapai hasil kerja yang oPT. imal.

Perusahaan mengukur kemampuan karyawan dalam bekerja dilihat dari produktivitas kerja. Menurut Wibowo (2016:95) produktivitas merupakan tentang seberapa baik suatu sistem operasi berfungsi dan indikator efisiensi dan daya saing dari suatu perusahaan atau departemen. Produktivitas adalah rasio keluaran terhadap masukan, merupakan ukuran efisiensi manajer dalam menggunakan sumber daya organisasi yang berbatas untuk menghasilkan barang dan jasa. Semakin besar nilai angka rasio semakin besar efisiensi.

PT. Xylo Indah Pratama merupakan perusahaan penanaman modal dalam negeri yang mempunyai andil dalam mengelola sumber daya alam yang berada di wilayah Kabupaten Musi Rawas. Visi PT. Xylo Indah Pratama adalah mewujudkan perusahaan manufaktur pensil terbesar dan terpadu yang berasaskan pengelolaan hutan secara lestari dengan cara memelihara sumber bahan baku dan tetap menjaga keseimbangan aspek lingkungan, sosial, dan ekonomi serta manfaat secara terus menerus dan berkelanjutan. Dengan misi menerapkan 10 prinsip dan kriteria FSC (Forest Stewardship Council), memperbaiki prosedur penebangan berdampak minimal, melaksanakan evaluasi dampak sosial dan menyusun rencana pemantauan, meningkatkan kualitas penebangan sesuai dengan konsep RIL dan COC melalui sosialisasi dan penerapan, efisiensi bahan baku dengan meningkatkan nilai tambah limbah semperan kayu yang diproduksi kembali menjadi slet, pembentukan kelompok tani dan membagikan bibit 100 ribu batang per tahun kepada petani mitra, swakelola limbah rumah tangga untuk dijadikan pupuk kompos dan membudayakan pemakaian pestisida organic oleh kelompok petani.

Pengamatan awal dapat diketahui bahwa karyawan belum memiliki keberanian untuk bekerja sendiri sehingga keyakinan karyawan masih kurang untuk mengerjakan pekerjaan yang dibebankan kepada karyawan. Karyawan dalam menyelesaikan pekerjaan belum bisa mengerjakan pekerjaan dengan efisien sehingga pekerjaan yang sebaiknya bisa diselesaikan ditunda karena rentang waktu yang diberikan masih ada, sehingga pekerjaan yang harus diselesaikan tertumpuk, jika waktu telah mendekati baru diselesaikan dan masih ada karyawan yang memiliki sifat tidak bisa menerima kritikan sehingga sulitnya melakukan perubahan yang lebih baik lagi.

Pengamawan awal yang dilakukan diketahui bahwa pengawasan Pimpinan masih kurang memberikan pengawasan terhadap staf atau karyawan, melainkan melakukan pengawasan kepada setiap bagian, sehingga karyawan kurang memahami apa yang harus dicapai, karena pimpinan dalam mengawasi tidak menjelaskan apa yang harus dicapai dan pimpinan kurang melakukan evaluasi hasil 
kerja karyawan, sehingga sering kali kesalahan yang sama terulang kembali pada pekerjaan yang sama. Selain itu di PT. Xylo Indah Pratama Kabupaten Musi Rawas diketahui belum maksimalnya dukungan dari atasan sehingga karyawan belum memiliki keyakinan dalam bekerja, dan belumoptimalnya dukungan dari sesama karyawan, maka dengan begitu mempengaruhi produktivitas kerja karyawan

\section{TINJAUAN PUSTAKA}

\subsection{Kompetensi}

Menurut Sudarmanto (2015:44) kompetensi adalah terminology yang sering didengar dan diucapkan banyak orang. Kita pun sering mendengar dan mengucapkan terminology itu dalam berbagai penggunaan, khususnya tarkait dengan pengembangan sumber daya manusia. Akan tetapi sering kali persepsi, pemahaman dan maksna terminology itu tidak sama atau saling dipertukarkan dengan terminology lain.

Menurut Ricard kompetensi adalah karakteristik-karakteristik yang berhubungan dengan kinerja unggul dan atau efektif di dalam pekerjaan, sedangkan Klem menyatakan kompetensi merupakan karakteristik mendasar seseorang yang menghasilkan kinerja unggul dana tau efektif dalam suatu pekerjaan (Sudarmanto, 2015: 46)

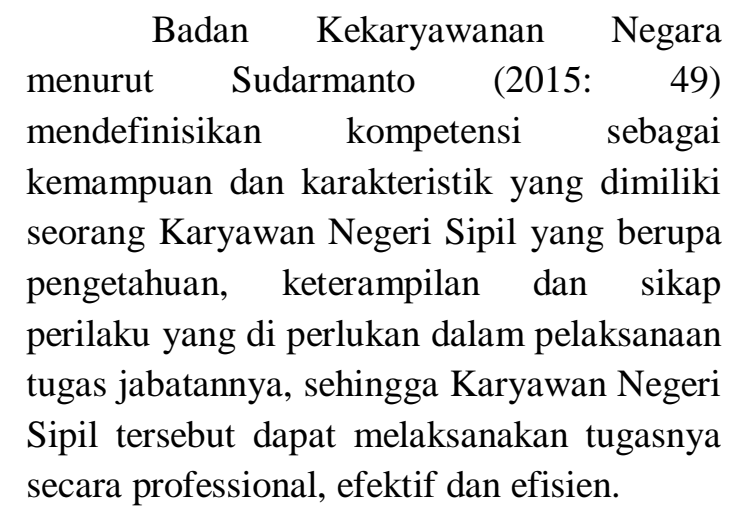

\subsection{Pengawasan}

Menurut Sedarmayanti (2017: 197) pengawasan SDM merupakan kegiatan yang dilakukan untuk mengendalikan pelaksanaan tugas/pekerjaan yang dilakukan seseorang agar proses pekerjaan sesuai dengan hasil yang diingiinkan.

Menurut Handoko (Tonny, 2013: 4) pengawasan adalah suatu usaha sistematik untuk menetapkan standar pelaksanaan dengan tujuan-tujuan perencanaan, merancang system informasi umpan balik, membandingkan kegiatan nyata dengan standar yang telah ditetapkan sebelumnya, menentukan dan mengukur penuimpanganpenyimpangan, serta mengambil kegiatan koreksi yang diperlihatkan untuk menjamin bahwa semua sumber daya perusahaan digunakan dan cara efektif dan efisien dalam mencapai tujuan-tujuan perusahaan.

Pengawasan adalah semua aktivitas yang dilaksanakan oleh pihak manajer dalam upaya memastikan bahwa hasil actual sesuai dengan hasil yang direncanakan (Tonny, 2013: 4)

\subsection{Produktivitas Kerja}

Menurut Belcher (Wibowo, 2016:93) produktivitas adalah hubungan antara keluaran atau hasil organisasi dengan masukan yang diperlukan. Produktivitas dapat dikuantifikasikan dengan membagi keluaran dengan masukan.

Menurut Wibowo (2016:95) produktivitas merupakan tentang seberapa baik suatu sistem operasi berfungsi dan indikator efisiensi dan daya saing dari suatu prusahaan atau departemen.

Menurut Sedarmayanti (2017:341) produktivitas adalah hubungan antara hasil nyata ataupun fisik (barang atau jasa) dan masukan yang sebenarnya.

\subsection{Penelitian Terdahulu}

1. Robiaful Akbar dan Jumiati Sasmita JOM Fekon Vol. 1 No. 2 Oktober 2014. Pengaruh pengawasan dan kompetensi terhadap produktivitas kerja karyawan pada Hotel Permai Pekanbaru. Penelitian ini dengan menggunakan metode kuantitatif. Hasil penelitian tentang pengawasan berpengaruh signifikan 
terhadap produktivitas kerja karyawan hotel permai pekanbaru, karena pimpinan tidak mengevaluasi hasil kerja setiap karyawan secara rutin ini dikarenakan kurangnya jumlah pengawas pada setiap bagian sehingga hasil kerja setiap karyawan tidak dapat dievaluasi dengan baik. Hasil penelitian tentang kompetensi berpengaruh signifikan terhadap produktivitas kerja karyawan hotel permai pekanbaru, karena kurangnya pengetahuan karyawan tentang pekerjaan menunjukkan bahwan karyawan kurang emmahami dan mengetahui tugas dan pekerjaan yang menjadi tanggung jawabnya sheingga memberikan pengaruh terhadap hasil kerja karyawan tersebut. Hasil penelitian tentang pengawasan dan kompetensi berpengaruh signifikan terhadap produktivitas kerja karyawan hotel permai pekanbaru, karena pengawasan dan kompetensi yang secara kualitas maupun kuantitas belum stabil, demikian juga pada persoalan pencapaian target, disiplin kerja, kemampuan berinovasi, bekerja sama antara sesame tekan kerja serta ketelitian dalam bekerja yang belum baik.

2. Rumimpunu, Ridel Clif Joune Jurnal EMBA 1243 Vol.3 No.3 Sept. 2015, Hal.1243-1253. Pengaruh Kompetensi Dan Stres Kerja Terhadap Kinerja Karyawan Pada Dinas Pendidikan Nasional Provinsi Sulut. Metode penelitian menggunakan analisis regresi linier berganda dengan responden sebanyak 65 orang. Hasil penelitian menunjukkan bahwa kompetensi dan stres kerja secara simultan berpengaruh positif dan signifikan terhadap kinerja karyawan. Sebaiknya Dinas Pendidikan Nasional Provinsi Sulawesi Utara agar dapat meningkatkan kinerja karyawan dengan melakukan perbaikan kompetensi secara terus-menerus.

3. Dr (Cand) Novianita Rulandari International Journal of Humanities and Social Science, Vol.7 No.2 Februari 2017. The effect of supervision and professionalism on staff performance at the office of social afairs in east Jakarta Admiinistrative City. This study used quantitative descriPT. ive approach in which 2 independent variabel an one dependent. The research shows that there is a positive influence of supervision and professionalism on staff performance at the office of social affairs in east Jakarta Administrative City, which finallu build causality relation mechanism.

\subsection{Hipotesis}

Hipotesis dalam penelitian ini adalah sebagai berikut:

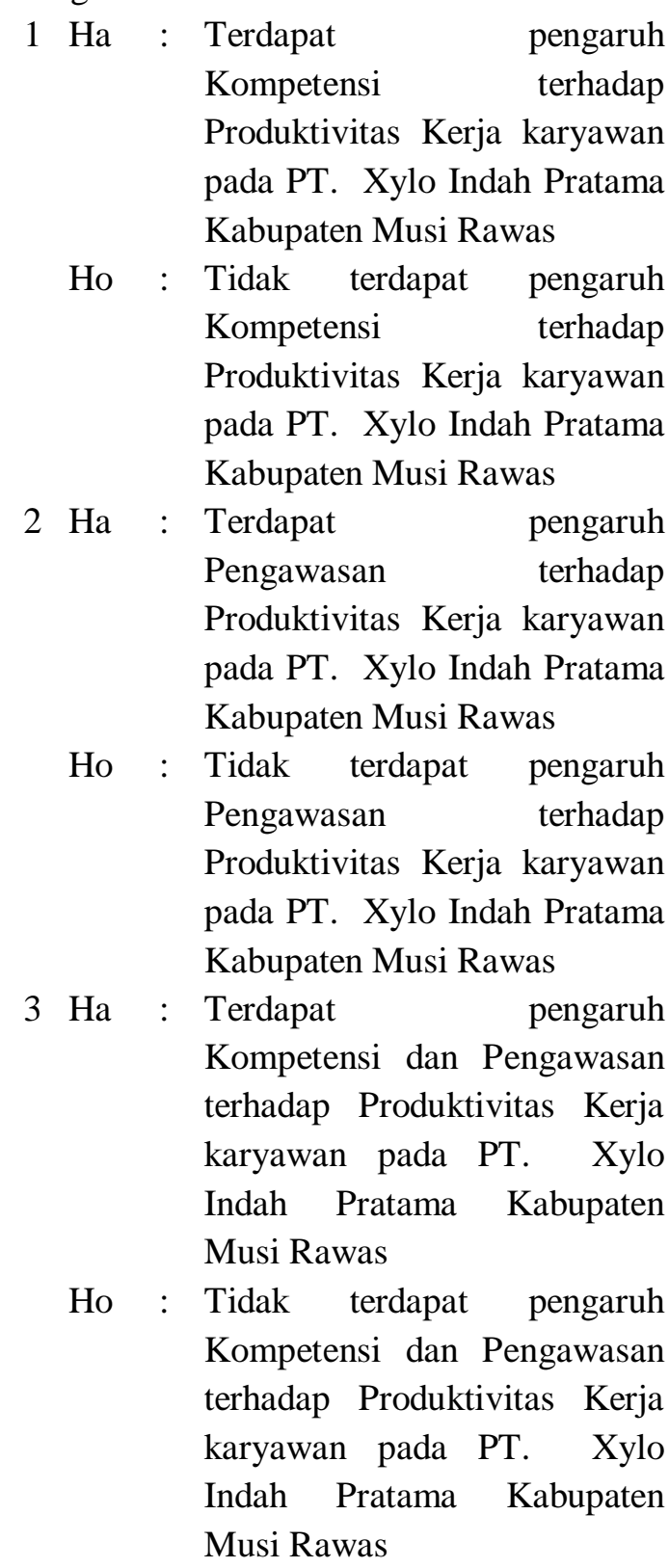




\subsection{Kerangka Penelitian}

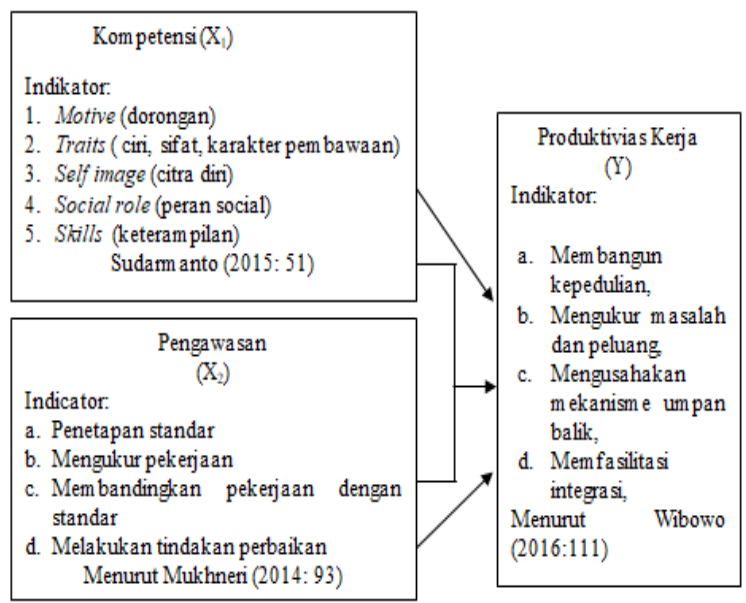

\section{Gambar 1}

\section{Kerangka Penelitian}

\section{METODOLOGI PENELITIAN}

\subsection{Desain Penelitian}

Jumlah karyawan sebanyak 346 karyawan PT. Xylo Indah Pratama Kabupaten Musi Rawas. Penelitian ini dengan tujuan penelitian untuk mengetahui pengaruh kompetensi dan pengawasan terhadap produktivitas kerja karyawan pada PT. Xylo Indah Pratama Kabupaten Musi Rawas. Metode penelitian yang digunakan adalah metode penelitian kuantitatif, teknik pengumpulan data yaitu kuisioner yang berisi daftar pernyataan yang berkaitan dengan variabel kompetensi, pengawasan dan produktivitas kerja karyawan. Teknik analisis data yang digunakan adalah dengan menggunakan regresi linear berganda, uji koefisien determinasi dan uji $\mathrm{F}$, regresi linear sederhana, uji koefisien korelasi dan uji t

\subsection{Populasi dan Sampel}

\section{Populasi}

Populasi dalam penelitian ini karyawan PT. Xylo Indah Pratama Kabupaten Musi Rawas berjumlah 346.

\section{Sampel Penelitian}

Teknik sampel yang digunakan dalam penelitian ini sampel jenuh adalah sensus, dimana semua anggota populasi dijadikan sampel. Adapun penentuan sampel dalam penelitian ini menggunakan rumus Slovin (Bambang, 2018: 137)

$\mathrm{n}=\frac{N}{1+N e^{2}}$

Keterngan

$\mathrm{n}=$ besaran Sampel

$\mathrm{N}=$ besaran Populasi

$\mathrm{E}=$ nilai kritis (batas ketelitian) yang diinginakn (persen kelonggaran ketidak telitian karena kesalahan penarikan sampel)

$\mathrm{n}=\frac{N}{1+N e^{2}}$

$=\frac{346}{1+346 \times 0.1^{2}}$

$=\frac{346}{1+3.46}$

$=\frac{346}{4.46}=77,57$

maka sampel dalam penelitian ini berjumlah 77 karyawan PT. Xylo Indah Pratama Kabupaten Musi Rawas yang dijadikan sampel dalam penelitian.

\subsection{Sumber Data}

sumber data yang digunakan dalam penelitian ini adalah data primer yaitu dengan menggukan kuisioner penelitian untuk mengetahui pengaruh kompetensi dan pengawasan terhadap produktivitas kerja karyawan pada PT. Xylo Indah Prtama Kabupaten Musi Rawas.

\subsection{Teknik Pengumpulan Data}

Teknik pengumpulan data penelitian yang biasa digunakan yaitu sebagai berikut observasi, dokumentasi dan kuesioner.

\section{HASIL DAN PEMBAHASAN \\ 4.1 Hasil Penelitian}

\section{Pengujian Instrumen Penelitian}

\section{a. Pengujian Validitas}

Hasil $r$ hitung kita bandingkan dengan $r$ tabel dimana $\mathrm{df}=\mathrm{n}-2$ dengan sig 5\%. Jika $r$ tabel < $r$ hitung maka maka valid. Uji validitas menggunakan teknik korelasi product moment. Pengujian validitas dilakukan di PT 
Lubuklinggau Lestari dengan menjawab pernyataan yang berkaitan dengan pengaruh kompetensi dan pengawasan terhadap produktivitas kerja karyawan, responden yang digunakan dalam pengujian validitas adalah sebanyak 25 karyawan.

Dari hasil pengujian diatas menunjukan hasil uji validitas variabel kompetensi $\left(\mathrm{X}_{1}\right)$ dari 15 (Lima belas) pertanyaan dengan sampel sebanyak 25 (Duapuluh Lima) responden dengan standar signifikan 0,05 (5\%). Dari sig 0,05 dengan 25 responden maka $r_{\text {tabel }}$ sebesar 0,396, jika $r_{\text {hitung }}>r_{\text {tabel }}$ maka data dinyatakan valid. Hal ini berarti bahwa semua item pertanyaan yang ada dalam kuisioner tersebut dapat dijadikan sabagai alat ukur yang valid dalam analisis selanjutnya.

Dari hasil pengujian diatas menunjukan hasil uji validitas variabel pengawasan $\left(\mathrm{X}_{2}\right)$ dari 12 (Dua belas) pertanyaan dengan sampel sebanyak 25 (Duapuluh Lima) responden dengan standar signifikan 0,05 (5\%). Dari sig 0,05 dengan 25 responden maka $r_{\text {tabel }}$ sebesar 0,396, jika $r_{\text {hitung }}>r_{\text {tabel }}$ maka data dinyatakan valid. Hal ini berarti bahwa semua item pertanyaan yang ada dalam kuisioner tersebut dapat dijadikan sabagai alat ukur yang valid dalam analisis selanjutnya.

Dari hasil pengujian diatas menunjukan hasil uji validitas variabel produktivitas kerja (Y) dari 12 (Dua belas) pertanyaan dengan sampel sebanyak 25 (Duapuluh Lima) responden dengan standar signifikan 0,05 (5\%). Dari sig 0,05 dengan 25 responden maka $r_{\text {tabel }}$ sebesar 0,396, jika $r_{\text {hitung }}>r_{\text {tabel }}$ maka data dinyatakan valid. Hal ini berarti bahwa semua item pertanyaan yang ada dalam kuisioner tersebut dapat dijadikan sabagai alat ukur yang valid dalam analisis selanjutnya.

\section{b. Pengujian Reliabilitas}

Uji reabilitas dapat dilakukan secara bersama-sama terhadap seluruh butir pertanyaan. Jika nilai alpha $>0,60$ maka reliable. Pengujian reliabilitas dilakukan di PT Lubuklinggau Lestari dengan menjawab pernyataan yang berkaitan dengan pengaruh kompetensi dan pengawasan terhadap produktivitas kerja karyawan, responden yang digunakan dalam pengujian validitas adalah sebanyak 25 karyawan. adapun hasil pengujian validitas yaitu sebagai berikut :

\section{Tabel 1}

\section{Pengujian Reliabilitas Variabel Kompetensi}

Reliability Statistics

\begin{tabular}{cc}
\hline Cronbach's Alpha & Nof Items \\
\hline 0.912 & 15 \\
\hline
\end{tabular}

Sumber: Hasil Pengolahan Data, pada SPSS Versi 17 (2019)

Dari tabel hasil uji reliabilitas variabel kompetensi $\left(\mathrm{X}_{1}\right)$ diatas, nilai korelasi Cronbach Alpha $=0,912$. Korelasi berada pada kategori sangat kuat. Bila berdasarkan kriteria maka dapat diketahui bahwa nilai Cronbach Alpha > 0,60 maka dengan demikian dapat disimpulkan bahwa kuisioner yang akan diuji dapat dinyatakan reliabel.

\section{Tabel 2}

Pengujian Reliabilitas Variabel Pengawasan Reliability Statistics

\begin{tabular}{cc}
\hline Cronbach's Alpha & Nof Items \\
\hline 0.871 & 12
\end{tabular}

Sumber: Hasil Pengolahan Data, pada SPSS Versi 17 (2019)

Dari tabel hasil uji reliabilitas variabel pengawasan $\left(\mathrm{X}_{2}\right)$ diatas, nilai korelasi Cronbach Alpha $=0,871$. Korelasi berada pada kategori sangat kuat. Bila berdasarkan kriteria maka 
dapat diketahui bahwa nilai Cronbach Alpha > 0,60 maka dengan demikian dapat disimpulkan bahwa kuisioner yang akan diuji dapat dinyatakan reliabel.

Tabel 3

Pengujian Reliabilitas Variabel Produktivitas Kerja

\begin{tabular}{cc}
\multicolumn{2}{c}{ Reliability Statistics } \\
\hline Cronbach's Alpha & N of Items \\
\hline 0.886 & 12
\end{tabular}

Sumber: Hasil Pengolahan Data, pada SPSS Versi 17 (2019)

Dari tabel hasil uji reliabilitas variabel kompetensi $\left(\mathrm{X}_{1}\right)$ diatas, nilai korelasi Cronbach Alpha $=0,886$. Korelasi berada pada kategori sangat kuat. Bila berdasarkan kriteria maka dapat diketahui bahwa nilai Cronbach Alpha > 0,60 maka dengan demikian dapat disimpulkan bahwa kuisioner yang akan diuji dapat dinyatakan reliabel.

\section{Uji Asumsi Klasik}

\section{a. Uji Normalitas Data}

Menurut (Sugiyono 2015:271) penggunaan statistik parametris mensyaratkan bahwa data setiap variabel yang akan di analisis harus berdistribusi normal. Oleh karena itu sebelum pengujian hipotesis dilakukan. Maka terlebih dahulu akan dilakukan uji normalitas data.Terdapat beberapa teknik untuk menguji normalitas data salah satunya adalah chi kuadrat.

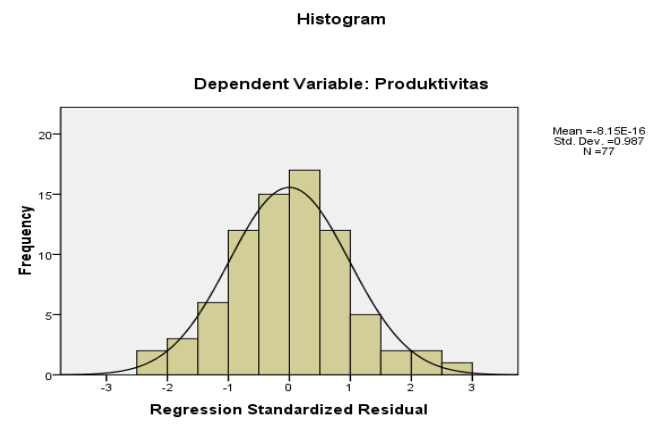

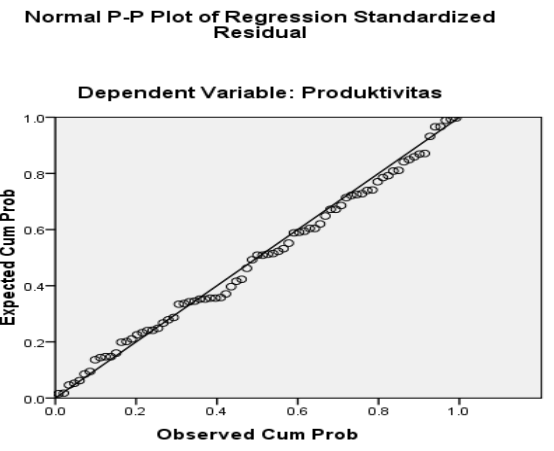

Sumber: Hasil Pengolahan Data, pada SPSS Versi 17 (2019)

Dengan melihat tampilan grafik histogram maupun normal plot dapat disimpulkan bahwa grafik histogram memberikan pola yang tidak menceng (skewness) dalam keadaan normal. Sedangkan grafik normal plot terlihat menyebar disekitar garis diagonal, merata yang mana dalam keadaan normal, maka dari hasil identifikasi gambar yang terdapat diatas maka dapat disimpulkan bahwa berdistribusi normal.

\section{Tabel 4}

Pengujian Reliabilitas

One-Sample Kolmogorov-Smirnov Test

\begin{tabular}{|c|c|c|c|c|}
\hline & & Kompetensi & Pengawasan & $\begin{array}{l}\text { Produk } \\
\text { tivitas }\end{array}$ \\
\hline \multicolumn{2}{|l|}{$N$} & 77 & 77 & 77 \\
\hline \multirow{2}{*}{$\begin{array}{l}\text { Normal } \\
\text { Parameters } \\
a, \text {,b }\end{array}$} & Mean & 61.2857 & 48.7273 & $\begin{array}{r}48.896 \\
1\end{array}$ \\
\hline & $\begin{array}{l}\text { Std. } \\
\text { Deviation }\end{array}$ & 3.60868 & 2.88205 & \begin{tabular}{|r|}
2.8863 \\
8
\end{tabular} \\
\hline \multirow{3}{*}{$\begin{array}{l}\text { Most } \\
\text { Extreme } \\
\text { Differences }\end{array}$} & Absolute & .105 & .106 & .122 \\
\hline & Positive & .071 & .086 & .122 \\
\hline & Negative & -.105 & -.106 & -.100 \\
\hline \multirow{2}{*}{\multicolumn{2}{|c|}{$\begin{array}{l}\text { Kolmogorov-Smirnov } \\
\text { Z } \\
\text { Asymp. Sig. (2-tailed) }\end{array}$}} & .920 & .927 & 1.071 \\
\hline & & .366 & .356 & .202 \\
\hline
\end{tabular}

Sumber: Hasil Pengolahan Data, pada SPSS Versi 17 (2019)

Untuk menganalisanya, dapat dilihat garis " Asymp, Sig. (2-tailed)" 
baris paling bawah. Bila nilai signifikan tiap variabel lebih dari $>0,05$ maka uji normalitas bisa terpenuhi. Berdasarkan hasil uji normalitas menunjukan bahwa nilai signifikan variabel kompetensi sebesar $\quad 0,366>0,05, \quad$ variabel pengawasan sebesar $0,356>0,05$, variabel produktivitas kerja sebesar $0,202>0,05$, dapat diambil kesimpulan bahwa nilai signifikan $>0,05$ sehingga data dnyatakan normal, dan uji normalitas terpenuhi secara normal. Dan data layak digunakan untuk analisis selanjutnya.

\section{a. Uji Linearitas Data}

Menurut Suliyanto (2015: 125) pengujian linearitas dilakukan untuk mengetahui apakah model yang dibuktikan merupakan model linear atau tidak. Hasil dari uji linearitas ini adalah informasi apakah model empiris sebaiknya linear, kuadrat atau kubik.Untuk mendeteksi apakah model sebaiknya menggunakan persamaam linear atau tidak, maka digunakan dengan metode analisis grafik dan metode statisitk. Metode statistik yang dapat digunakan untuk melakukan pengujian linearitas adalah DurbinWatson Test, Ramsey Test, LM Test dan MWD Test.

Perhitungan pada uji ini penulis dibantu program SPSS 17. Uji linearitas menggunakan metode Duebin-Waston d statisitk (the Durbin-Waston d Statistic Test) Suliyanto (2015: 107), metode ini metode yang sangat popular untuk pengujian spesifikasi model, terutama untuk mengetahui ada tidaknya otokorelasi dalam suatu model regresi.
Tabel 5

Pengujian Uji Linearitas

\begin{tabular}{|c|c|c|c|c|c|c|c|c|}
\hline \multicolumn{9}{|c|}{ ANOVA } \\
\hline & & & & $\begin{array}{c}\text { Sum of } \\
\text { Squares }\end{array}$ & $d f$ & $\begin{array}{l}\text { Mean } \\
\text { Square }\end{array}$ & $\mathrm{F}$ & Sig. \\
\hline $\begin{array}{l}\text { Kompet } \\
\text { ensi }\end{array}$ & $\begin{array}{l}\text { Betw } \\
\text { een } \\
\text { Grou } \\
\text { ps } \\
\text { Within } \\
\text { Total }\end{array}$ & $\begin{array}{l}\text { Line } \\
\text { ar } \\
\text { Ter } \\
\mathrm{m} \\
\text { Group }\end{array}$ & $\begin{array}{l}\text { (Combin } \\
\text { ed) } \\
\text { Weighte } \\
d \\
\text { Deviatio } \\
n \\
\text { os }\end{array}$ & $\begin{array}{l}569.544 \\
422.612 \\
146.933 \\
420.170 \\
989.714\end{array}$ & $\begin{array}{l}63 \\
76\end{array}$ & $\begin{array}{r}43.811 \\
422.61 \\
2 \\
12.244 \\
6.669\end{array}$ & $\begin{array}{r}6.569 \\
63.36 \\
6 \\
1.836\end{array}$ & $\begin{array}{l}.000 \\
.061\end{array}$ \\
\hline $\begin{array}{l}\text { Pengaw } \\
\text { asan }\end{array}$ & $\begin{array}{l}\text { Betw } \\
\text { een } \\
\text { Grou } \\
\text { ps }\end{array}$ & $\begin{array}{l}\text { Line } \\
\text { ar } \\
\text { Ter } \\
m \\
\text { Group }\end{array}$ & $\begin{array}{l}\text { (Combin } \\
\text { ed) } \\
\text { Weighte } \\
d \\
\text { Deviatio } \\
n \\
\text { os }\end{array}$ & $\begin{array}{c}442.427 \\
410.498 \\
31.929 \\
188.845 \\
631.273\end{array}$ & $\begin{array}{l}63 \\
76\end{array}$ & $\begin{array}{r}34.033 \\
410.49 \\
8 \\
2.661 \\
\\
2.998\end{array}$ & $\begin{array}{r}11.35 \\
4 \\
136.9 \\
45 \\
.888\end{array}$ & $\begin{array}{l}.000 \\
.000 \\
.564\end{array}$ \\
\hline
\end{tabular}

Sumber: Hasil Pengolahan Data, pada SPSS Versi 17 (2019)

Hasil uji linearitas membuktikan bahwa pengaruh yang terjadi antara variabel bebasnya dengan variabel terikat bersifat linear, paba tabel diatas menunjukan uji pengaruh bersifat linear antara kompetensi terhadap produktivitas kerja karyawan nilai Sig pada Linearity sebesar $0,061>0,05$. Dan juga menunjukan uji pengaruh bersifat linear antara pengawasan terhadap produktivitas kerja karyawan dengan Sig pada Linearitu sebessar 0.564>0.05 Apabila nilai signifikan lebih besar dari 0,05 maka dapat diartikan hubungan prediktor dan dependen variabel bersifat linear, maka kedua signifikan pada tabel anova memenuhi syarat linear.

\section{Pengujian Analisa Statistik}

a. Pengaruh Kompetensi terhadap Produktivitas Kerja Karyawan pada PT Xylo Indah Pratama Kabupaten Musi Rawas

\section{1) Regresi Linear Sederhana}

Analisis data dalam penelitian ini adalah dengan menggunakan bantuan 
SPSS (Statitiscal product and service solution) versi 17,0 for windows melalui pengolahan data yang didapat dari kuisioner dengan metode Persamaan Umum Regresi Linear sederhana bertujuan untuk meneliti sejauh mana pengaruh kompetensi terhadap produktivitas kerja karyawan pada PT. Xylo Indah Pratama Kabupaten Musi Rawas, adapun hasil penelitian yaitu sebagai berikut:

Tabel 6

Regresi Linear

Coefficients ${ }^{a}$

\begin{tabular}{|l|r|r|r|r|r|}
\hline & \multicolumn{1}{|c|}{$\begin{array}{c}\text { Unstandardized } \\
\text { Coefficients }\end{array}$} & $\begin{array}{c}\text { Standardi } \\
\text { zed } \\
\text { Coefficien } \\
\text { ts }\end{array}$ & & \\
\cline { 2 - 4 } & \multicolumn{1}{|c|}{$\mathrm{B}$} & $\begin{array}{c}\text { Std. } \\
\text { Error }\end{array}$ & Beta & $\mathrm{t}$ & Sig. \\
\hline 1 (Constant) & 16.864 & 4.292 & & 3.929 & .000 \\
Kodel & .523 & .070 & .653 & 7.476 & .000 \\
\hline a. Dependent Variable: Produktivitas & & & \\
\hline
\end{tabular}

Sumber: Hasil Pengolahan Data, pada SPSS Versi 17 (2019)

Persamaan regresi yang digunakan adalah $\mathrm{Y}=\mathrm{a}+\mathrm{bX}$, maka dapat dihasilkan persamaan dari output adalah $\mathrm{Y}=16.864+0.523 \mathrm{X}$, maka hasil output SPSS maka diketahui coefficients kompetensi sebesar 0.523 merupakan koefisien regresi, yang berarti jika instansi meningkatkan 1 satuan maka akan meningkatkan sebesar 0.523 Dan standard error sebesar 0.070 merupakan penyimpangan dari konstanta yang ada dalam persamaan regresi.

\section{2) Uji Koefisien Korelasi}

Koefesien korelasi adalah teknik analisis data untuk mengetahui hubungan kompetensi/pengawasan terhadap produktivitas kerja karyawan pada PT. Xylo Indah Pratama Kabupaten Musi Rawas.
Tabel 7

Uji Koefisien Korelasi

Model Summary

\begin{tabular}{|l|c|r|r|c|}
\hline Model & $\mathrm{R}$ & $\begin{array}{c}\mathrm{R} \\
\text { Square }\end{array}$ & $\begin{array}{c}\text { Adjusted R } \\
\text { Square }\end{array}$ & $\begin{array}{c}\text { Std. Error of the } \\
\text { Estimate }\end{array}$ \\
\hline 1 & $.653^{\mathrm{a}}$ & .427 & .419 & 2.19940 \\
\hline
\end{tabular}

Sumber: Hasil Pengolahan Data, pada SPSS Versi 17 (2019)

Hasil pengolahan data menunjukan bahwa nilai $\mathrm{R}$ atau Multiple $\mathrm{R}$ menunjukan korelasi antara variabel bebas dengan variabel terikat sebesar 0.653 Dalam hal ini karena regresi linear sederhana dapat diketahui bahwa variabel bebas maka diakatakan bahwa korelasi antara kompetensi terhadap produktivitas kerja karyawan adalah sebesar $65.3 \%$, dan sisanya (100-65.3) $34.7 \%$ dipengaruhi oleh variabel lain yang tidak termasuk dalam variabel penelitian.

\section{3) Uji t}

Uji parsial (Uji t) dilakukan untuk membuktikan hipotesis apakah terdapat pengaruh kompetensi/pengawasan terhadap produktivitas kerja karyawan pada PT. Xylo Indah Pratama Kabupaten Musi Rawas. Pada taraf kepercayaan 95\% atau taraf signifikan $\alpha=0,05$ dapat dilakukan hipotesis regresi secara bersama dengan menggunakan analisis variabel (Uji t). Suatu data dikatakan terdapat pengaruh jika $t_{\text {hitung }}>t_{\text {tabel }}$ ini berarti Ho ditolak dan Ha diterima begitu juga sebaliknya jika $t_{\text {hitung }}<t_{\text {tabel }}$ ini berarti Ho diterima dan Ha ditolak. Dari data hasil pengujian maka independent yang dimasukan kedalam model regresi variabel maka dapat diketahui bahwa untuk mengetahui apakah kompetensi terhadap produktivitas kerja karyawan, didapatkan nilai $t_{\text {hitung }}$ sebesar 7.476 dan $t_{\text {tabel }}$ adalah sebesar 1,292 (nilai $t_{\text {tabel }} n=77$ ) maka dengan demikian dapat diketahui bahwa jika kriteria sesuai dengan $t_{\text {hitung }}>t_{\text {tabel }}$ 
maka Ho ditolak dan Ha diterima, yang artinya terdapat pengaruh kompetensi terhadap produktivitas kerja karyawan pada PT Xylo Indah Pratama Kabupaten Musi Rawas.

\section{b. Pengaruh Pengawasan terhadap Produktivitas Kerja Karyawan pada PT Xylo Indah Pratama Kabupaten Musi Rawas \\ 1) Regresi Linear Sederhana}

Analisis data dalam penelitian ini adalah dengan menggunakan bantuan SPSS (Statitiscal product and service solution) versi 17,0 for windows melalui pengolahan data yang didapat dari kuisioner dengan metode Persamaan Umum Regresi Linear sederhana bertujuan untuk meneliti sejauh mana pengaruh pengawasan terhadap produktivitas kerja karyawan pada PT. Xylo Indah Pratama Kabupaten Musi Rawas.

\section{Tabel 8}

\section{Regresi Linear}

\begin{tabular}{|c|c|c|c|c|c|}
\hline \multicolumn{6}{|c|}{ Coefficients $^{a}$} \\
\hline \multirow[b]{2}{*}{ Model } & \multicolumn{2}{|c|}{$\begin{array}{l}\text { Unstandardized } \\
\text { Coefficients }\end{array}$} & \multirow{2}{*}{$\begin{array}{c}\begin{array}{c}\text { Standardized } \\
\text { Coefficients }\end{array} \\
\text { Beta }\end{array}$} & \multirow[b]{2}{*}{$t$} & \multirow[b]{2}{*}{ Sig. } \\
\hline & $B$ & Std. Error & & & \\
\hline 1 (Constant) & 9.544 & 3.338 & & 2.859 & .005 \\
\hline Pengawasan & .808 & .068 & .806 & 11.809 & .000 \\
\hline
\end{tabular}

a. Dependent Variable: Produktivitas

Sumber: Hasil Pengolahan Data, pada SPSS Versi 17 (2019)

Persamaan regresi yang digunakan adalah $\mathrm{Y}=\mathrm{a}+\mathrm{bX}$, maka dapat dihasilkan persamaan dari output adalah $\mathrm{Y}=9.544+0.808 \mathrm{X}$, maka hasil output SPSS maka diketahui coefficients pengawasan sebesar 0.808 merupakan koefisien regresi, yang berarti jika instansi meningkatkan 1 satuan maka akan meningkatkan sebesar 0.808 Dan standard error sebesar 0.068 merupakan penyimpangan dari konstanta yang ada dalam persamaan regresi.

\section{2) Uji Koefisien Korelasi}

Koefesien korelasi adalah teknik analisis data untuk mengetahui hubungan kompetensi/pengawasan terhadap produktivitas kerja karyawan pada PT. Xylo Indah Pratama Kabupaten Musi Rawas.

Tabel 9

Uji Koefisien Korelasi

\begin{tabular}{|l|c|r|r|r|}
\hline Model & $\mathrm{R}$ & $\begin{array}{c}\mathrm{R} \\
\text { Square }\end{array}$ & $\begin{array}{c}\text { Adjusted R } \\
\text { Square }\end{array}$ & $\begin{array}{c}\text { Std. Error of } \\
\text { the Estimate }\end{array}$ \\
\hline 1 & $.806^{\mathrm{a}}$ & .650 & .646 & 1.71829 \\
\hline
\end{tabular}
a. Predictors: (Constant), Pengawasan

Sumber: Hasil Pengolahan Data, pada SPSS Versi 17 (2019)

Hasil pengolahan data menunjukan bahwa nilai $\mathrm{R}$ atau Multiple $\mathrm{R}$ menunjukan korelasi antara variabel bebas dengan variabel terikat sebesar 0.806 Dalam hal ini karena regresi linear sederhana dapat diketahui bahwa variabel bebas maka diakatakan bahwa korelasi antara pengawasan terhadap produktivitas kerja karyawan adalah sebesar $80.6 \%$, dan sisanya (100-80.6) $19.4 \%$ dipengaruhi oleh variabel lain yang tidak termasuk dalam variabel penelitian.

\section{3) Uji t}

Uji parsial (Uji t) dilakukan untuk membuktikan hipotesis apakah terdapat pengaruh pengawasan terhadap produktivitas kerja karyawan pada PT. Xylo Indah Pratama Kabupaten Musi Rawas. Adapun hasil penelitian yaitu: 


\section{Tabel 10}

Uji t

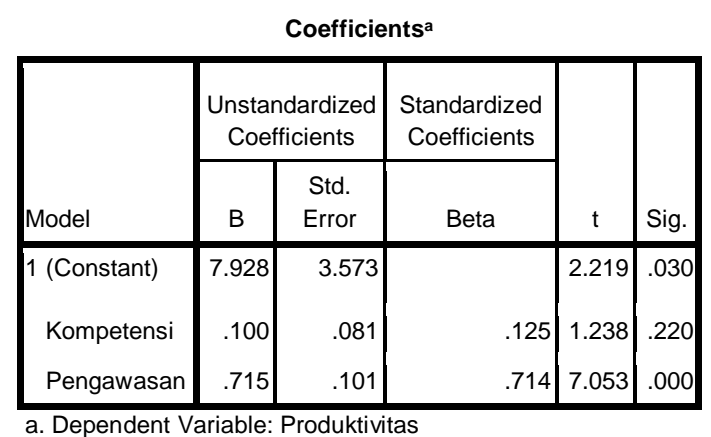

Sumber: Hasil Pengolahan Data, pada SPSS Versi 17 (2019)

Pada taraf kepercayaan $95 \%$ atau taraf signifikan $\alpha=0,05$ dapat dilakukan hipotesis regresi secara bersama dengan menggunakan analisis variabel (Uji t ). Suatu data dikatakan terdapat pengaruh jika $t_{\text {hitung }}>t_{\text {tabel }}$ ini berarti Ho ditolak dan Ha diterima begitu juga sebaliknya jika $t_{\text {hitung }}<t_{\text {tabel }}$ ini berarti Ho diterima dan Ha ditolak. Dari data hasil pengujian maka independent yang dimasukan kedalam model regresi variabel maka dapat diketahui bahwa untuk mengetahui apakah pengawasan terhadap produktivitas kerja karyawan, didapatkan nilai $t_{\text {hitung }}$ sebesar 11.809 dan $t_{\text {tabel }} l$ adalah sebesar 1,292 (nilai $t_{\text {tabel }} n=77$ ) maka dengan demikian dapat diketahui bahwa jika kriteria sesuai dengan $t_{\text {hitung }}>t_{\text {tabel }}$ maka Ho ditolak dan $\mathrm{Ha}$ diterima, yang artinya terdapat pengaruh pengawasan terhadap produktivitas kerja karyawan pada PT Xylo Indah Pratama Kabupaten Musi Rawas.

\section{c. Pengaruh Kompetensi dan Pengawasan terhadap Produktivitas Kerja Karyawan pada PT Xylo Indah Pratama Kabupaten Musi Rawas \\ 1) Regresi Linear Berganda}

Menggunakan analisis regresi linier berganda menurut Sugiyono (2015: 255) digunakan oleh peneliti, bila peneliti bermaksud meramalkan keadaan (naik turunya) variabel devenden (kriterium), bila dua atau lebih variabel independen sebagai faktor-faktor prediktor dimanipulasi (naik turunkan nilainya). Jadi analisis regresi ganda akan dilakukan bila jumlah variabel independennya minimal 2 (dua). Persamaan yang digunakan untuk menganalisa pengaruh kompetensi dan pengawasan terhadap produktivitas kerja karyawan pada PT. Xylo Indah Pratama Kabupaten Musi Rawas.

Tabel 11

Regresi Linear

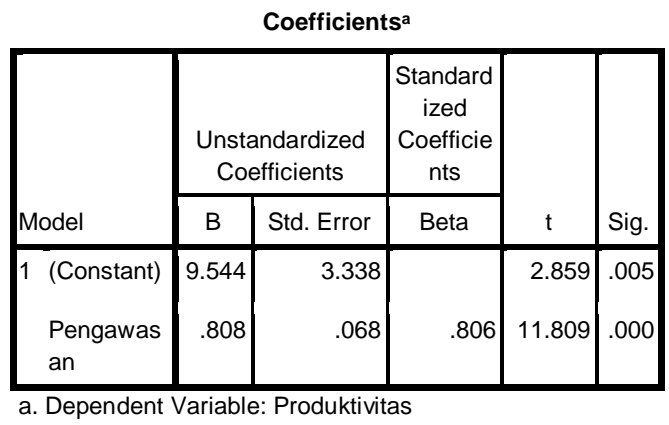

Sumber: Hasil Pengolahan Data, pada SPSS Versi 17 (2019)

Berdasarkan hasil perhitungan output SPSS diperoleh nilai $\mathrm{b} 1=0.100$ b2 $=0.715$ dan nilai a $=7.928$ kemudian $\mathrm{a}$ dan $\mathrm{b}$ disusun ke dalam persamaan regresi linear berganda $\mathrm{Y}=\mathrm{a}+\mathrm{b}_{1} \mathrm{X}_{1}$ $+\mathrm{b}_{2} \mathrm{X}_{2}$ maka persamaan regresinya adalalah $\mathrm{Y}=7.928+0.100 \mathrm{X}_{1}+0.715 \mathrm{X}_{2}$. Itu artinya persamaan tersebut adalah bahwa nilai konstanta (a) sebesar 7.928 ini berarti bahwa apabila tidak ada penigkatan variabel kompetensi dan pengawasan maka produktivitas kerja karyawan sebesar 7.928, sedangkan nilai koefisien regresi (b1) sebesar 0,100 ini artinya terjadinya peningkat pada satuan variabel kompetensi maka akan meningkatkan produktivitas kerja karyawan sebesar 0.100 satuan. Kemudian nilai koefisien regresi (b2) 
sebesar 0,715 ini berarti setiap terjadi peningkatan satu satuan variabel pengawasan akan meningkatkan produktivitas kerja karyawan sebesar 0,715 satuan

\section{2) Uji Koefisien Determinasi}

Koefisien determinasi $\left(\mathrm{R}^{2}\right)$ pada intinya mengukur seberapa jauh kemampuan model dalam menerangkan variasi variabel dependen. Nilai koefisien determinasi adalah antara nol sampai satu $\left(0<\mathrm{R}^{2}<1\right)$. Nilai $\mathrm{R}^{2}$ yang kecil berarti 39 kemampuan variabelvariabel independen dalam menjelaskan variasi variabel dependen sangat terbatas. Nilai yang mendekati satu berarti variabel-variabel independen memberikan hampir semua informasi yang dibutuhkan untuk memprediksi variasi variabel dependen.

Tabel 12

Uji Koefisien Determinasi

\begin{tabular}{|c|c|c|c|c|}
\hline \multicolumn{5}{|c|}{ Model Summary } \\
\hline Model & $\mathrm{R}$ & $\begin{array}{c}\mathrm{R} \\
\text { Square }\end{array}$ & $\begin{array}{c}\text { Adjusted R } \\
\text { Square }\end{array}$ & $\begin{array}{l}\text { Std. Error of the } \\
\text { Estimate }\end{array}$ \\
\hline 1 & $.811^{\mathrm{a}}$ & .657 & .648 & 1.71222 \\
\hline
\end{tabular}

Sumber: Hasil Pengolahan Data, pada SPSS Versi 17 (2019)

Dari hasil perhitungan koefisien determinasi diatas, maka dapat diketahui bahwa nilai $\mathrm{R}^{2}$ adalah 0,657 maka dikali dengan $100 \%$ didapatkan nilai sebesar $81.6 \%$ artinya pengaruh kompetensi dan pengawasan terhadap produktivitas kerja karyawan pada PT Xylo Indah Pratama Kabupaten Musi Rawas adalah sebesar $65.7 \%$ sedangkan sisanya (100-65.7) $34.3 \%$ dipengaruhi variabel lain yang tidak termasuk dalam penelitian.

\section{3) Uji F}

Uji F dibantu dengan program SPSS 17. Menurut Suliyanto (2015: 491)
Untuk menguji pengaruh kompetensi dan pengawasan terhadap produktivitas kerja pada PT. Xylo Indah Pratama Kabupaten Musi Rawas.

$$
\text { Jika } \quad F_{\text {hitung }}>F_{\text {tabel }} \text { maka }
$$
signifikan ini berarti Ho ditolak dan $\mathrm{Ha}$ diterima, sedangkan jika $F_{\text {hitung }}<F_{\text {tabel }}$ maka tidak signifikan berarti Ha ditolak dan Ho diterima. Tarif signifikan $\alpha 0,05$ (5\%). Diperoleh nilai $F_{\text {hitung }}$ sebesar 70.986 dan $F_{\text {tabel }}$ sebesar 3.12 Ini menunjukan bahwa $F_{\text {hitung }}>F_{\text {tabel }}$ dan juga sig sebesar 0,000 $<0,05$ sehingga dapat diketahui bahwa pengaruhnya signifikan. Maka dengan demikian dapat diambil kesimbulan bahwa Ho ditolak dan $\mathrm{Ha}$ diterima. Artinya terdapat pengaruh kompetensi dan pengawasan terhadap produktivitas kerja karyawan pada PT Xylo Indah Pratama Kabupaten Musi Rawas.

\subsection{Pembahasan}

\section{Pengaruh Kompetensi terhadap} Produktivitas Kerja Karyawan pada PT Xylo Indah Pratama Kabupaten Musi Rawas

Persamaan Umum Regresi Linear sederhana bertujuan untuk meneliti sejauh mana pengaruh kompetensi terhadap produktivitas kerja karyawan pada PT. Xylo Indah Pratama Kabupaten Musi Rawas, adapun hasil penelitian yaitu persamaan regresi yang digunakan adalah $\mathrm{Y}=\mathrm{a}+\mathrm{bX}$, maka dapat dihasilkan persamaan dari output adalah $\mathrm{Y}=16.864+0.523 \mathrm{X}$, maka hasil output SPSS maka diketahui coefficients kompetensi sebesar 0.523 merupakan koefisien regresi, yang berarti jika instansi meningkatkan 1 satuan maka akan meningkatkan sebesar 0.523 Dan standard error sebesar 0.070 merupakan penyimpangan dari konstanta yang ada dalam persamaan regresi.

Koefesien korelasi adalah teknik analisis data untuk mengetahui hubungan kompetensi/pengawasan terhadap 
produktivitas kerja karyawan pada PT. Xylo Indah Pratama Kabupaten Musi Rawas. Hasil pengolahan data menunjukan bahwa nilai $\mathrm{R}$ atau Multiple $\mathrm{R}$ menunjukan korelasi antara variabel bebas dengan variabel terikat sebesar 0.653 Dalam hal ini karena regresi linear sederhana dapat diketahui bahwa variabel bebas maka diakatakan bahwa korelasi antara kompetensi terhadap produktivitas kerja karyawan adalah sebesar $65.3 \%$, dan sisanya (100-65.3) $34.7 \%$ dipengaruhi oleh variabel lain yang tidak termasuk dalam variabel penelitian.

Uji parsial (Uji t) dilakukan untuk membuktikan hipotesis apakah terdapat pengaruh kompetensi/pengawasan terhadap produktivitas kerja karyawan pada PT. Xylo Indah Pratama Kabupaten Musi Rawas hasil pengujian maka independent yang dimasukan kedalam model regresi variabel maka dapat diketahui bahwa untuk mengetahui apakah kompetensi terhadap produktivitas kerja karyawan, didapatkan nilai $t_{\text {hitung }}$ sebesar 7.476 dan $t_{\text {tabel }}$ adalah sebesar 1,292 (nilai $t_{\text {tabel }} n=77$ ) maka dengan demikian dapat diketahui bahwa jika kriteria sesuai dengan $t_{\text {hitung }}>t_{\text {tabel }}$ maka Ho ditolak dan Ha diterima, yang artinya terdapat pengaruh kompetensi terhadap produktivitas kerja karyawan pada PT Xylo Indah Pratama Kabupaten Musi Rawas.

\section{Pengaruh Pengawasan terhadap Produktivitas Kerja Karyawan pada PT Xylo Indah Pratama Kabupaten Musi Rawas}

Persamaan Umum Regresi Linear sederhana bertujuan untuk meneliti sejauh mana pengaruh pengawasan terhadap produktivitas kerja karyawan pada PT. Xylo Indah Pratama Kabupaten Musi Rawas, persamaan regresi yang digunakan adalah $\mathrm{Y}$ $=\mathrm{a}+\mathrm{bX}$, maka dapat dihasilkan persamaan dari output adalah $\mathrm{Y}=9.544+0.808 \mathrm{X}$, maka hasil output SPSS maka diketahui coefficients pengawasan sebesar 0.808 merupakan koefisien regresi, yang berarti jika instansi meningkatkan 1 satuan maka akan meningkatkan sebesar 0.808 Dan standard error sebesar 0.068 merupakan penyimpangan dari konstanta yang ada dalam persamaan regresi.

Koefesien korelasi adalah teknik analisis data untuk mengetahui hubungan kompetensi/pengawasan terhadap produktivitas kerja karyawan pada PT. Xylo Indah Pratama Kabupaten Musi Rawas. Hasil pengolahan data menunjukan bahwa nilai $\mathrm{R}$ atau Multiple $\mathrm{R}$ menunjukan korelasi antara variabel bebas dengan variabel terikat sebesar 0.806 Dalam hal ini karena regresi linear sederhana dapat diketahui bahwa variabel bebas maka diakatakan bahwa korelasi antara pengawasan terhadap produktivitas kerja karyawan adalah sebesar $80.6 \%$, dan sisanya (100-80.6) $19.4 \%$ dipengaruhi oleh variabel lain yang tidak termasuk dalam variabel penelitian.

Uji parsial (Uji t) dilakukan untuk membuktikan hipotesis apakah terdapat pengaruh pengawasan terhadap produktivitas kerja karyawan pada PT. Xylo Indah Pratama Kabupaten Musi Rawas. Adapun hasil didapatkan nilai $t_{\text {hitung }}$ sebesar 11.809 dan $t_{\text {tabe }}$ adalah sebesar 1,292 (nilai $t_{\text {tabel }}$ $\mathrm{n}=77$ ) maka dengan demikian dapat diketahui bahwa jika kriteria sesuai dengan $\mathrm{t}_{\text {hitung }}>\mathrm{t}_{\text {tabel }}$ maka Ho ditolak dan Ha diterima, yang artinya terdapat pengaruh pengawasan terhadap produktivitas kerja karyawan pada PT Xylo Indah Pratama Kabupaten Musi Rawas.

3. Pengaruh Kompetensi dan Pengawasan terhadap Produktivitas Kerja Karyawan pada PT Xylo Indah Pratama Kabupaten Musi Rawas

Menggunakan analisis regresi linier berganda menurut Sugiyono (2015: 255) digunakan oleh peneliti, bila peneliti bermaksud meramalkan keadaan (naik turunya) variabel devenden (kriterium), bila dua atau lebih variabel independen sebagai faktor-faktor prediktor dimanipulasi (naik turunkan nilainya). Jadi analisis regresi 
ganda akan dilakukan bila jumlah variabel independennya minimal 2 (dua). Persamaan yang digunakan untuk menganalisa pengaruh kompetensi dan pengawasan terhadap produktivitas kerja karyawan pada PT. Xylo Indah Pratama Kabupaten Musi Rawas. hasil perhitungan output SPSS diperoleh nilai $\mathrm{b} 1=$ 0.100 b2 $=0.715$ dan nilai a $=7.928$ kemudian a dan $\mathrm{b}$ disusun ke dalam persamaan regresi linear berganda $\mathrm{Y}=\mathrm{a}$ $+b_{1} X_{1}+b_{2} X_{2}$ maka persamaan regresinya adalalah $\mathrm{Y}=7.928+0.100 \mathrm{X}_{1}+0.715 \mathrm{X}_{2}$. Itu artinya persamaan tersebut adalah bahwa nilai konstanta (a) sebesar 7.928 ini berarti bahwa apabila tidak ada penigkatan variabel kompetensi dan pengawasan maka produktivitas kerja karyawan sebesar 7.928, sedangkan nilai koefisien regresi (b1) sebesar 0,100 ini artinya terjadinya peningkat pada satuan variabel kompetensi maka akan meningkatkan produktivitas kerja karyawan sebesar 0.100 satuan. Kemudian nilai koefisien regresi (b2) sebesar 0,715 ini berarti setiap terjadi peningkatan satu satuan variabel pengawasan akan meningkatkan produktivitas kerja karyawan sebesar 0,715 satuan

Koefisien determinasi $\left(\mathrm{R}^{2}\right)$ pada intinya mengukur seberapa jauh kemampuan model dalam menerangkan variasi variabel dependen. Nilai koefisien determinasi adalah antara nol sampai satu $\left(0<\mathrm{R}^{2}<1\right)$. Nilai $\mathrm{R}^{2}$ yang kecil berarti 39 kemampuan variabelvariabel independen dalam menjelaskan variasi variabel dependen sangat terbatas. Nilai yang mendekati satu berarti variabelvariabel independen memberikan hampir semua informasi yang dibutuhkan untuk memprediksi variasi variabel dependen hasil perhitungan koefisien determinasi diatas, maka dapat diketahui bahwa nilai $\mathrm{R}^{2}$ adalah 0,657 maka dikali dengan $100 \%$ didapatkan nilai sebesar $81.6 \%$ artinya pengaruh kompetensi dan pengawasan terhadap produktivitas kerja karyawan pada PT Xylo Indah Pratama Kabupaten Musi Rawas adalah sebesar $65.7 \%$ sedangkan sisanya
(100-65.7) $34.3 \%$ dipengaruhi variabel lain yang tidak termasuk dalam penelitian.

Uji F dibantu dengan program SPSS 17. Menurut Suliyanto (2015: 491) Untuk menguji pengaruh kompetensi dan pengawasan terhadap produktivitas kerja pada PT. Xylo Indah Pratama Kabupaten Musi Rawas. Diperoleh nilai $F_{\text {hitung }}$ sebesar 70.986 dan $F_{\text {tabel }}$ sebesar 3.12 Ini menunjukan bahwa $F_{\text {hitung }}>F_{\text {tabel }}$ dan juga sig sebesar $0,000<0,05$ sehingga dapat diketahui bahwa pengaruhnya signifikan. Maka dengan demikian dapat diambil kesimbulan bahwa Ho ditolak dan $\mathrm{Ha}$ diterima. Artinya terdapat pengaruh kompetensi dan pengawasan terhadap produktivitas kerja karyawan pada PT Xylo Indah Pratama Kabupaten Musi Rawas.

\section{KESIMPULAN}

Berdasarkan hasil penelitian dan pembahasan maka dapat disimpulkan bahwa:

1. Pengujian hipotesis pertama untuk mengetahui apakah kompetensi terhadap produktivitas kerja karyawan, didapatkan nilai thitung sebesar 7.476 dan $t_{\text {tabel }}$ adalah sebesar 1,292 (nilai $t_{\text {tabel }}$ $\mathrm{n}=77$ ) maka dengan demikian dapat diketahui bahwa jika kriteria sesuai dengan $t_{\text {hitung }}>t_{\text {tabel }}$ maka Ho ditolak dan Ha diterima, yang artinya terdapat pengaruh kompetensi terhadap produktivitas kerja karyawan pada PT Xylo Indah Pratama Kabupaten Musi Rawas.

2. Pengujian hipotesis kedua untuk mengetahui pengaruh pengawasan terhadap produktivitas kerja karyawan pada PT. Xylo Indah Pratama Kabupaten Musi Rawas. Adapun hasil didapatkan nilai $\mathrm{t}_{\text {hitung }}$ sebesar 11.809 dan $t_{\text {tabe }} l$ adalah sebesar 1,292 (nilai $t_{\text {tabel }}$ $\mathrm{n}=77$ ) maka dengan demikian dapat diketahui bahwa jika kriteria sesuai dengan $t_{\text {hitung }}>t_{\text {tabel }}$ maka Ho ditolak dan Ha diterima, yang artinya terdapat pengaruh pengawasan terhadap 
produktivitas kerja karyawan pada PT Xylo Indah Pratama Kabupaten Musi Rawas.

3. Hipotesis ketiga untuk mengetahui pengaruh kompetensi dan pengawasan terhadap produktivitas kerja pada PT. Xylo Indah Pratama Kabupaten Musi Rawas. Diperoleh nilai $F_{\text {hitung }}$ sebesar 70.986 dan $F_{\text {tabel }}$ sebesar 3.12 Ini menunjukan bahwa $\mathrm{F}_{\text {hitung }}>\mathrm{F}_{\text {tabel }}$ dan juga sig sebesar $0,000<0,05$ sehingga dapat diketahui bahwa pengaruhnya signifikan. Maka dengan demikian dapat diambil kesimpulan bahwa Ho ditolak dan $\mathrm{Ha}$ diterima. Artinya terdapat pengaruh kompetensi dan pengawasan terhadap produktivitas kerja karyawan pada PT Xylo Indah Pratama Kabupaten Musi Rawas

\section{SARAN}

Adapun saran-saran sebagai berikut:

1. Agar penelitian ini dapat digunakan sebagai masukan atau gambaran bagi penelitian selanjutnya yang akan melakukan penelitian dengan adanya kesamaan variabel penelitian walaupun berbeda tempat penelitian. Serta peneliti juga berharap agar untuk peneliti selanjutnya dapat menambah variabel bebas ataupun variabel terikat sehingga adanya pengembangan dari penelitian yang telah dilakukan peneliti

2. Kompetensi

Karyawan agar dapat meningkatkan kompetensi yang dimiliki untuk mampu memaksimalkan produktivitas kerja karyawan.

3. Pengawasan

Pengawasan yang dilakukan agar mampu lebih rinci, sehingga mampu meminimalisir terjadinya kesalahan dalam bekerja.

4. Produktivitas Kerja

a. Pimpinan dapat memberikan standar ataupun target kerja agar dapat maksimal dalam bekerja b. Seluruh bagian agar dapat saling bekerjsama untuk dapat mencapai target dan tujuan dalam bekerja sehingga produktivitas kerja karyawan dapat meningkat

\section{DAFTAR PUSTAKA}

[1] Sugiyono. 2015. Metode Penelitian Manajemen Bisnis. Bandung: Alfabeta.

[2] Prasetyo Bambang. 2018. Metode Penelitian Kuantitatif. Rajawali Pers: Jakarta.

[3] My Linh Nguyen.2017. The Impact of Employees Motivation on Organizational Effectivenes.

[4] Rumimpunu, Ridel Clif Joune. Jurnal EMBA 1243 Vol.3 No.3 Sept. 2015, Hal.1243-1253. Pengaruh Kompetensi Dan Stres Kerja Terhadap Kinerja Karyawan Pada Dinas Pendidikan Nasional Provinsi Sulut.

[5] Sedarmayanti. 2017. Perencanaan dan Pengembangan Sumber Daya Manusia. Jakarta: Refika Aditam.

[6] Suandi Putra Syamsuddin.2014. Pengaruh Motivasi Dan Pengalaman Kerja Terhadap Produktivitas Kerja Karyawan PT. . Suzuki Diana Motor Cabang Palopo.

[7] Sujarweni. 2014. Metodologi Penelitian Lengkap, Praktis dan Mudah Dipahami. Yogyakarta: PT. Pustaka Baru.

[8] Wibowo. 2016. Manajemen Kinerja. Edisi Kelima. Jakarta: Raja Grasiondo Persada. 